\title{
Spindle cell lipoma: An uncommon variant of lipoma affecting the foot sole
}

\author{
Nesrine Ben Salah ${ }^{1}$, Ines Lahouel ${ }^{1}$, Linda Manaa ${ }^{1}$, Monia Youssef $^{1}$, hichem hajali ${ }^{1}$, and \\ Jameleddine Zili ${ }^{1}$ \\ ${ }^{1}$ Fattouma Bourguiba University Hospital of Monastir
}

January 18, 2022

\begin{abstract}
We report a 36-year-old male with an atypical variant of lipoma occurring on an atypical site.
\end{abstract}

\section{Introduction :}

Spindle cell lipoma is a rare histologically distinct variant of lipoma which rarely occurs on the foot and exceptionally involves the sole. We report an atypical case of SCL localized on the foot sole.

\section{Case report :}

A 36-year-old male presented to our dermatological department for painful swelling of the sole of the right foot. The lesion started 6 years ago and the patient had no history of trauma. It progressively increased in size and caused a limp when walking. The clinical examination revealed a $5^{*} 3 \mathrm{~cm}$ single tumor of the right foot, mobile, not painful on palpation with normal overlying skin (Figure 1). The lymph nodes were free. Face and profile radiographs of the foot were normal. The ultrasound showed a circumscribed mass measuring $48^{*} 30^{*} 26 \mathrm{~mm}$, non-vascularized with heterogeneous tissue that was isoechoic in comparison to the fat tissue. Magnetic resonance imaging demonstrated that it was a multi-lobulated lesion with a fat signal on all sequences. This tumor was located in the extra aponeurotic subcutaneous soft tissue of the sole without deep extension (Figure 2). The Tumor was clinically diagnosed as lipoma. The lesion was excised with the removal of lobulated lipomatous mass weighing $32 \mathrm{~g}$ and measuring $5^{*} 3^{*} 3 \mathrm{~cm}$. It was encapsulated with a well-limited surface. Histological examination of the tumor confirmed a well-circumscribed lipomatous mass composed of proliferating of mature adipocytes arranged in lobules separated by fibrous septa. There were rare places of cellular fibrous spans with spindle cells arranged in bundles. There was no cell atypia, lipoblasts, nor mitotic figures (Figure 3A). Immunohistochemical staining of spindle cells was strongly positive for CD 34, while negative for S-100 protein (Figure 3B). These findings were consistent with the diagnosis of benign Spindle cell lipoma.

\section{Discussion :}

We describe an atypical case of Spindle cell lipoma localized on the foot sole. Lipomas of the sole have been rarely reported due to the relative paucity of adipose tissue at this region. Spindle cell lipoma is a rare benign adipose tissue tumor that settles frequently on the back and neck of middle-aged men. ${ }^{1}$ It is characterized by a slow and asymptomatic course, as in our case. To our knowledge, only 3 cases of Spindle cell lipoma involving the sole of the foot have been reported. ${ }^{2-4}$ The diagnosis of lipoma was suspected by magnetic resonance imagery, which represents the gold standard investigation of soft tissue tumors of the foot. In addition to histopathological examination, the immunohistochemical examination is necessary for differential diagnosis because of the similarity of Spindle cell lipoma and many benign and malignant 
soft tissue tumors. It has to be differentiated from cellular angiolipoma, myofibroblastoma, solitary fibrous tumor and mainly spindle cell liposarcoma. Spindle cell lipoma is characteristically composed of a mixture of mature adipocytes and bland spindle cells without significant variation in adipocyte size and shape nor atypical stroma cells. ${ }^{5}$

Rare lipoblasts maybe showed but are never a prominent finding. CD 34 was positively expressed in this tumor. Our results also confirmed these reports. Surgical excision remains the only treatment.

Authorship: All authors had access to the data and a role in writing this manuscript.

\section{Author contributions :}

The authors fulfill the ICMJE Criteria for Authorship and contributed equally.

Dr Nesrine Ben Salah, is the guarantor of the content of the manusript, included the data and analysis. Dr Ines Lahouel contributed to interpretation of data and revision of the manuscript. Dr Linda Manaa contributed to data collection. Dr Monia Youssef contributed to analysis and interpretation of data, revised it critically. Dr zili jamaleddine and Hichem Belhadjali contributed to final approval of the version of the manuscript to be submitted.

\section{Consent :}

The patient in this manuscript has given written informed consent to the publication of the case details.

\section{References:}

1. Ko JS, Daniels B, Emanuel PO, et al. Spindle Cell Lipomas in Women: A Report of 53 Cases. Am J SurgPathol. 2017;41:1267-74.

2. Math KR, Pavlov H, DiCarlo E, Bohne WH. Spindle cell lipoma of the foot: a case report and literature review. Foot Ankle Int. 1995;16:220-6.

3. Chen S, Huang H, He S, et al. Spindle cell lipoma: clinicopathologic characterization of 40 cases. Int J Clin Exp Pathol. 2019;12:2613-21.

4. Austin CD, Tiessen JR, Gopalan A, et al. Spindle Cell Lipoma of the Foot and the Application of CD34 Immunohistochemistry to Atypical Lipomatous Tumors in Unusual Locations. Appl Immunohistochem Mol Morphol. 2000;8:222-227.

5. Nonaka S, Enomoto K, Kawabori S, et al. Spindle cell lipoma within the larynx: a case report with correlated light and electron microscopy. ORL J Oto-Rhino-Laryngol Its Relat Spec. 1993;55:147-9

Figure legends:

Figure 1 : Painful swelling on the right foot sole.

Figure 2 : Magnetic resonance imaging showing a multi-lobulated lesion with a fat signal on all sequences, located in the extra aponeurotic subcutaneous soft tissue of the sole without deep extension.

Figure 3: (A) Excisional biopsy showed lobules of mature adipocytes, a bland spindle cell proliferation admixed with eosinophilic collagen bundles (Hematoxylin-eosin $\times 200$ ) ; (B) Spindle cells with immunoreactivity for CD34 $(\times 200)$. 


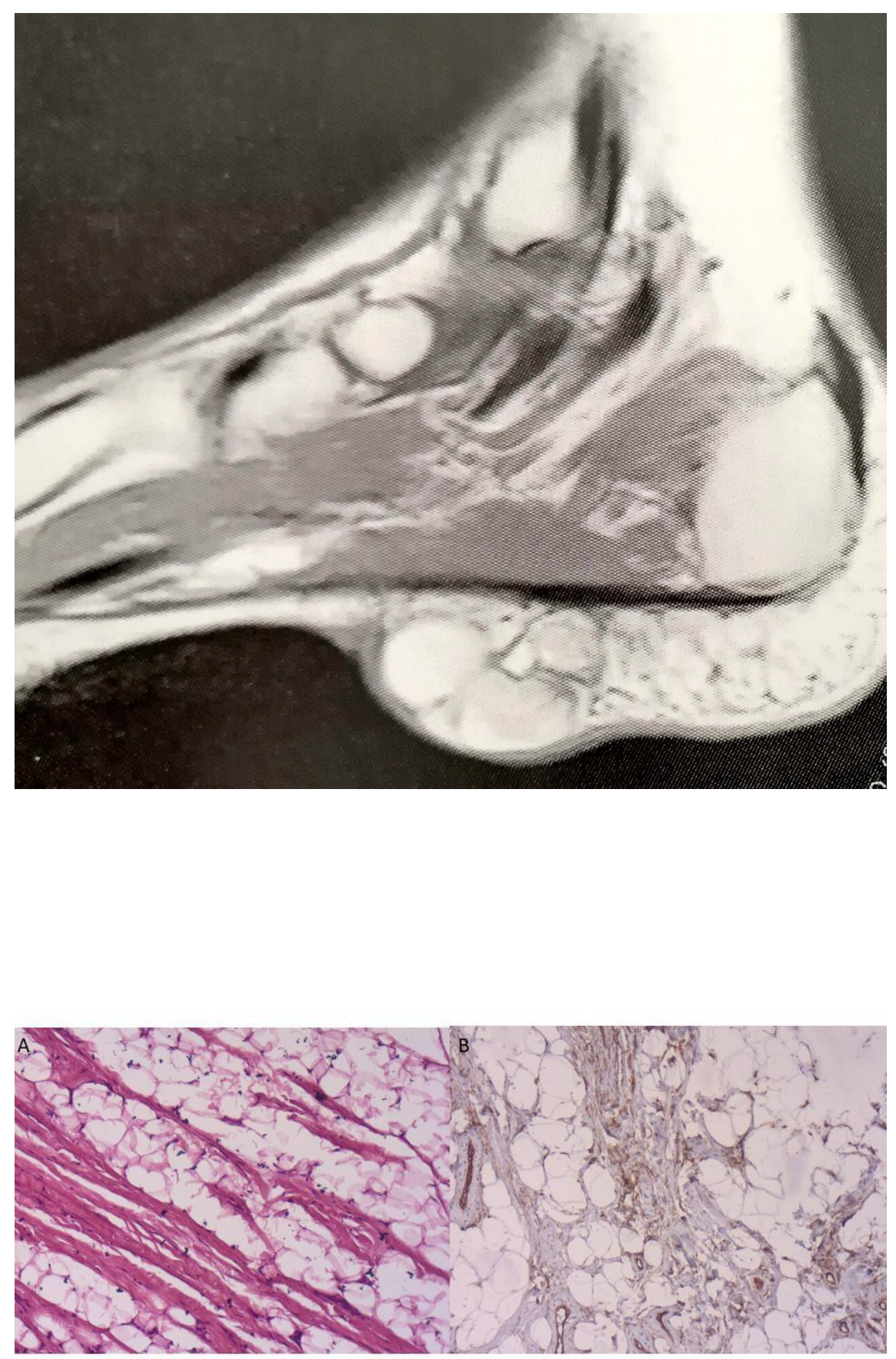